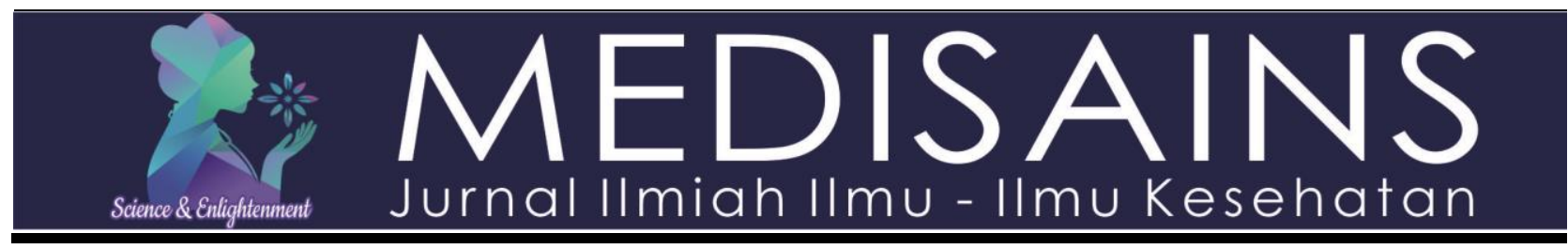

Review Article

\title{
A review on reducing the incidence of postoperative ileus by chewing gum, consuming coffee or warm water post abdominal surgery
} Tria Anisa Firmanti ${ }^{1}$, Tintin Sukartini, llya Krisnana

${ }^{1}$ Faculty of Nursing Universitas Airlangga, Surabaya, Indonesia

\section{ARTICLE INFORMATION}

Received: March 03, 2020

Revised: March 23, 2020

Available online: April 30, 2020

\section{KEYWORDS}

Chewing gum; Coffee; Water; lleus; Nausea

\section{CORRESPONDENCE}

Phone: 081331802409

E-mail: tintin-s@fkp.unair.ac.id

\section{A B S T R A C T}

Background: Postoperative ileus is the main complication post abdominal surgery; it signs two or more periods of vomiting and nausea, intolerance of diet more than 24 hours, inability to pass flatus more than 24 hours, and abdomen distension. Several studies are stating that interventions chewing gum, consuming coffee, and drinking warm water can reduce the incidence of postoperative ileus.

Objective: Collects the evidence for effect chewing gum, consuming coffee, and warm water to reduce postoperative ileus.

Method: This systematic review is arranged based on literature studies from five databases last five years, such as Scopus, Sciencedirect, Proquest, and Oxford, with the comprehensive survey, which conducted according to the guidelines in the PRISMA. We searched for studies with the keyword "chewing gum" OR "coffee" OR "warm water" AND "postoperative."

Result: We selected 215 articles from an electronic database, and 17 articles with Randomized Control Trials (RCTs) method included. The sampling of selected items in this systematic review carried for five months to 1 year, from January to December 2010 - 2017, obtained 20 to 975 samples. There was a significant effect of chewing gum, consuming coffee, and warm water reduced postoperative ileus incidence without side effects.

Conclusion: Chewing gum, consuming coffee, and warm water, are effective, safe, and not expensive to reduce the incidence of postoperative ileus and improve recovery post abdominal surgery.

\section{INTRODUCTION}

Postoperative ileus, gastric distension, and abdominal distension are the most common occurrence in abdominal surgery ${ }^{1,2}$. Postoperative ileus is the occurrence of two periods of nausea and vomiting or more, more than 24 hours of tolerance to the diet, flatus does not appear more than 24 hours, and abdominal distension ${ }^{3}$. Postoperative ileus and abdominal distension increase due to prolonged abdominal distension, nausea, vomiting, abdominal pressure, cramps, and pain in the patient, which causes prolonged recovery process ${ }^{4,5}$. Protracted postoperative ileus can reduce patient comfort, increase morbidity, mortality, and increase the length of hospital stay, higher maintenance costs, and delayed first food intake and failure of mobilization ${ }^{6}$. Several strategies and interventions have been carried out to prevent postoperative ileus both pharmacologically and non-pharmacologically, such as early mobilization and giving mineral water two hours after surgery but these interventions have not been effective in reducing postoperative ileus in abdominal surgery ${ }^{6}$

Postoperative ileus reported as 10 to $30 \%$ occurring in cases of abdominal surgery, according to previous studies, the incidence is different from one survey to another ${ }^{7-}$ 14. Postoperative ileus in Korea reported to be around $17.4 \%-24 \%$ is a common complication that occurs after major abdominal surgery ${ }^{15}$. Postoperative ileus incidence has happened in post-laparotomy gynecological surgery patients in China $14 \%{ }^{16}$. An average of $10 \%-30 \%$ of post abdominal surgery patients have postoperative ileus ${ }^{17}$. Postoperative ileus in colorectal surgery was $14 \%$, research conducted in the USA ${ }^{18}$. Postoperative gastric patients in Indonesia, approximately $30 \%-50 \%$, experienced 
prolongation of bowel sounds, and flatus 24 to 72 hours. Postoperative ileus problems cannot be resolved four days after surgery reported about $50 \%$ of events and will become prolonged postoperative ileus (PPOI) if not resolved for more than five days.

Postoperative ileus can increase due to pain fiber stimulation, excessive sympathetic nerve stimulation, and stress response that is influenced by nitric oxide release, intestinal vasoactive peptide, and $P$ substance. These mechanisms occur because of the reaction of inhibited neurotransmitter in the abdomen manipulated and peritoneal irritation 16. Postoperative lleus symptoms include abdominal discomfort, nausea, and vomiting, which are the leading causes of delayed enteral diet and patient recovery. The factors affecting are visceral manipulation, inflammatory mediators, anesthesia, and giving opioids to reduce pain ${ }^{15}$. Risk factors that can increase the incidence of postoperative ileus are cigarette users, low body weight, oral antibiotics in pre-surgery, preparation for abdominal repair, and surgery ${ }^{3}$. Patients with postoperative ileus will cause delayed oral food intake, wound healing, decreased immune system, increased septic complications, and hospital stay. It is essential to restore the digestive system function of postoperative patients to normal as soon as possible and prevent postoperative ileus $4,5,19-21$.

The most important part of postoperative patient care that nurses must do is increasing the prevention of postoperative complications. Some studies suggested that the prevention of postoperative complications can reduce complications and problems in preoperative and postoperative care ${ }^{22,23}$. Nursing interventions provided to prevent complications of the digestive system include exercise in patients, pain management, early postoperative mobilization, initiation of initial oral intake ${ }^{24-27}$. Chewing Gum is reported to reduce postoperative ileus, it is a safe, comfortable and inexpensive intervention, chewing gum is one type of sham feeding by seeing, smelling and eating without swallowing so that it can stimulate the cephalic vagal pathway ${ }^{15}$. Responses of giving warm water to postoperative patients also have positive effects on intestinal motility such as, eliminating gastrointestinal spasm and restoring intestinal peristalsis. Giving a little water to the patient undergoing bile duct surgery during the early postoperative stage is useful in regaining digestive function and preventing oral complications ${ }^{22}$. The next intervention that also provides health benefits is coffee, and research showed that consuming coffee after colectomy surgery is safe and can restore intestinal motility quickly ${ }^{28}$.

Based on the evidence-based on some literature on abdominal postoperative interventions, this systematic review was done to gather evidence that chewing gum, consuming coffee, and warm water can reduce postoperative intestinal ileus. The previous systematic review only discussed the benefits of chewing gum or drinking coffee only, while in this systematic review discussed together with the intervention of chewing gum, drinking coffee, and warm water to reduce post-operative ileus.

\section{METHOD}

\section{Search strategy}

We used PRISMA statement guidelines in preparing this systematic review. We searched the articles through the Scopus, Sciencedirect, Proquest, and Oxford database, by using the keywords "chewing gum" OR "coffee" OR "warm water" AND "postoperative" (Table 1).

Tabel 1. Search List

\begin{tabular}{ll}
\hline Find the database & Keyword \\
\hline Sopus $=32$ & chewing gum "OR" \\
Science Direct $=63$ & coffee "OR" \\
Proquest $=98$ & warm water "AND" \\
Oxford $=22$ & Postoperative \\
\hline
\end{tabular}

\section{Study Selection}

The articles we chose were the original articles published in the last five years (2015-2019). The articles discuss the intervention of chewing gum or consuming coffee or warm water to reduce postoperative ileus in post abdominal surgery patients. Paper that uses the Randomized Control Trial (RCTs) research method included, and we exclude articles that discuss chewing gum or consuming coffee or warm water combined and or compared with other interventions.

\section{Data extraction}

The articles criteria included in this systematic review were (1) articles related to the prevention of postoperative ileus, (2) the patient's criteria were postoperative abdominal patients, (3) the interventions carried out by giving chewing gum, warm water and coffee, (4) The expected research results are the first time bowel noise, flatus, defecation and length of stay (LOS).

\section{RESULTS}

The article search results obtained 215 articles consisting of 32 Scopus articles, 63 Science Direct articles, 98 Proquest articles, and 22 Oxford articles. The identification was according to the inclusion and exclusion criteria contained 11 items on the chewing gum intervention, six reports on coffee, and warm water intervention. The remaining 194 items excluded because they were not original articles, in the form of systematic reviews, did not use the RCTs method, in combination with other interventions, and the respondents were not postoperative abdominal patients. The expected results in 17 articles that have identified showed improvement in the first time bowel sounds, flatus, defecation, and LOS. 


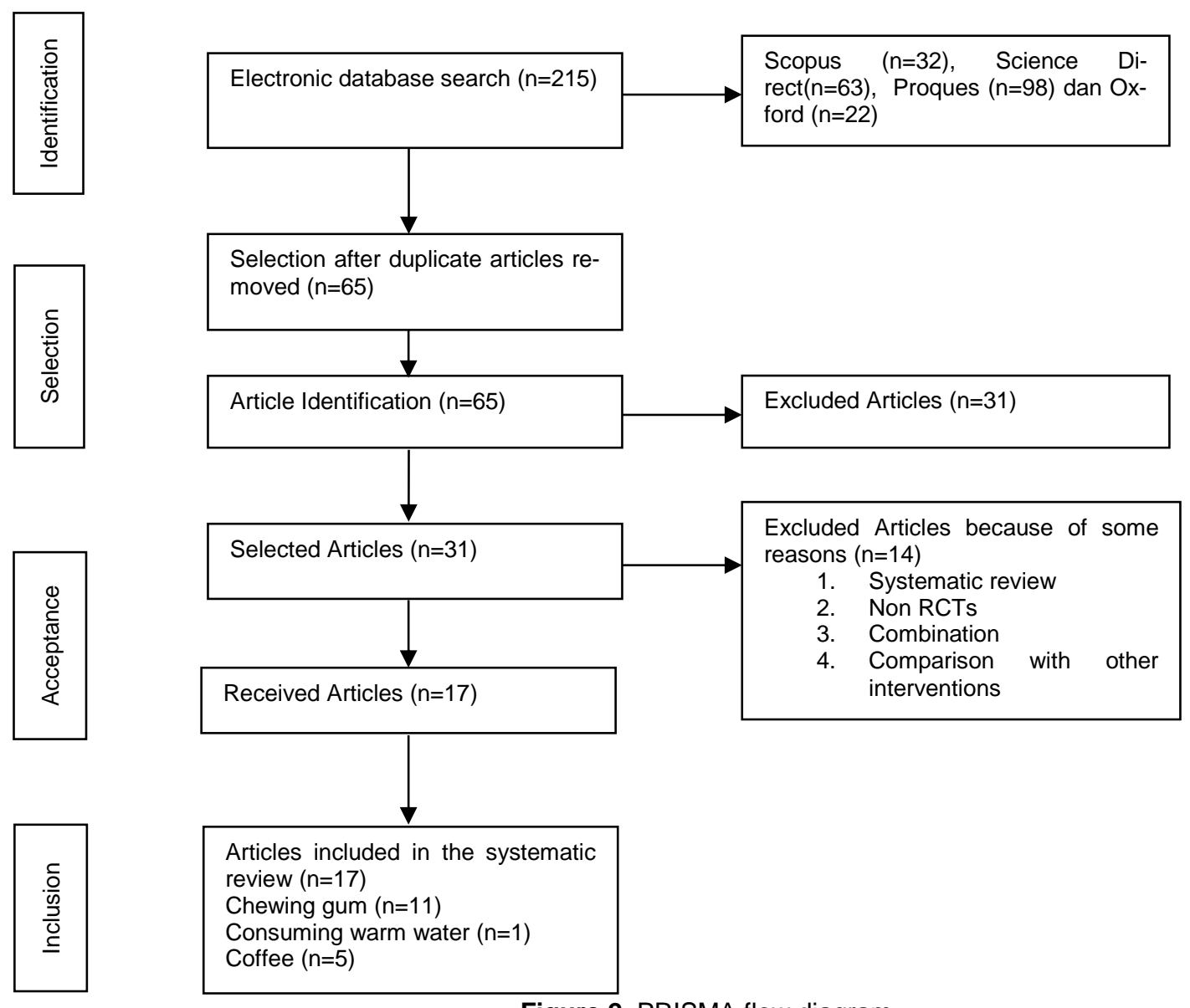

Figure 2. PRISMA flow diagram

\section{Study characteristics}

The article selection process has included in the PRISMA flow diagram presented in figure 1, and sample characteristics, intervention, outcome, and result in the included studies described in table 2 . The sampling of selected articles in this systematic review was carried out for five months to 1 year, from January to December 2010-2017 and obtained 200 to 1000 samples, because there was a drop out in the study, the respondents became 20-975 in each group.

The selected articles in this systematic review used the division of intervention and nonintervention group; there were also articles which consisted of 3 groups. Fourteen paper was composed of two groups, including an intervention group and a nonintervention group. The intervention group, and the nonintervention group with standard postoperative interventions. The regular gum-chewing group, and the nicotine gum-chewing group. The coffee-drinking group and the control group with routine room interventions, the coffee-drinking group and the warm water drinking control group, the coffee-drinking group and the drinking water control group, the friendly drinking water group and the control group with routine interventions in the room. Three articles were consisting of 3 groups; the first was the xylitol gum group, the nonxylitol gum group, and the control group. The second articles were the coffee drinking group with caffeine, the decaffeinated coffee drinking group, and the drinking water group, and the third articles were the chewing gum group, the coffee-drinking group, and the warm water-drinking group.

Interventions on these patients carried out in several countries, including Korea, Japan, Turkey, Iran, Australia, Thailand, Taiwan, the Netherlands, the United Kingdom, and the USA. The following inclusion criteria patients over 18 years old, scheduled to be open elective or laparoscopic bowel surgery, fasting for 8 hours preoperative, stable vital signs, no general complications during surgery, no history of diabetes, hypothyroidism, neuromuscular disease, diarrhea, chronic constipation, abdominal irritation syndrome, gastroesophageal reflux and exclusion criteria for swallowing difficulty or risk of choking (post-stroke), risk of aspiration, planned stoma, cognitive impairment, history of analgesic use, electrolyte imbalance, pneumonia or peritonitis, history of abdominal surgery, postoperative complications, dental problems, wearing dentures, not understanding informed consent, patients with acute or chronic cardiovascular disease, liver disease, kidney disease, pregnancy, breastfeeding, patients with sudden surgery, and hypersensitive to coffee. 


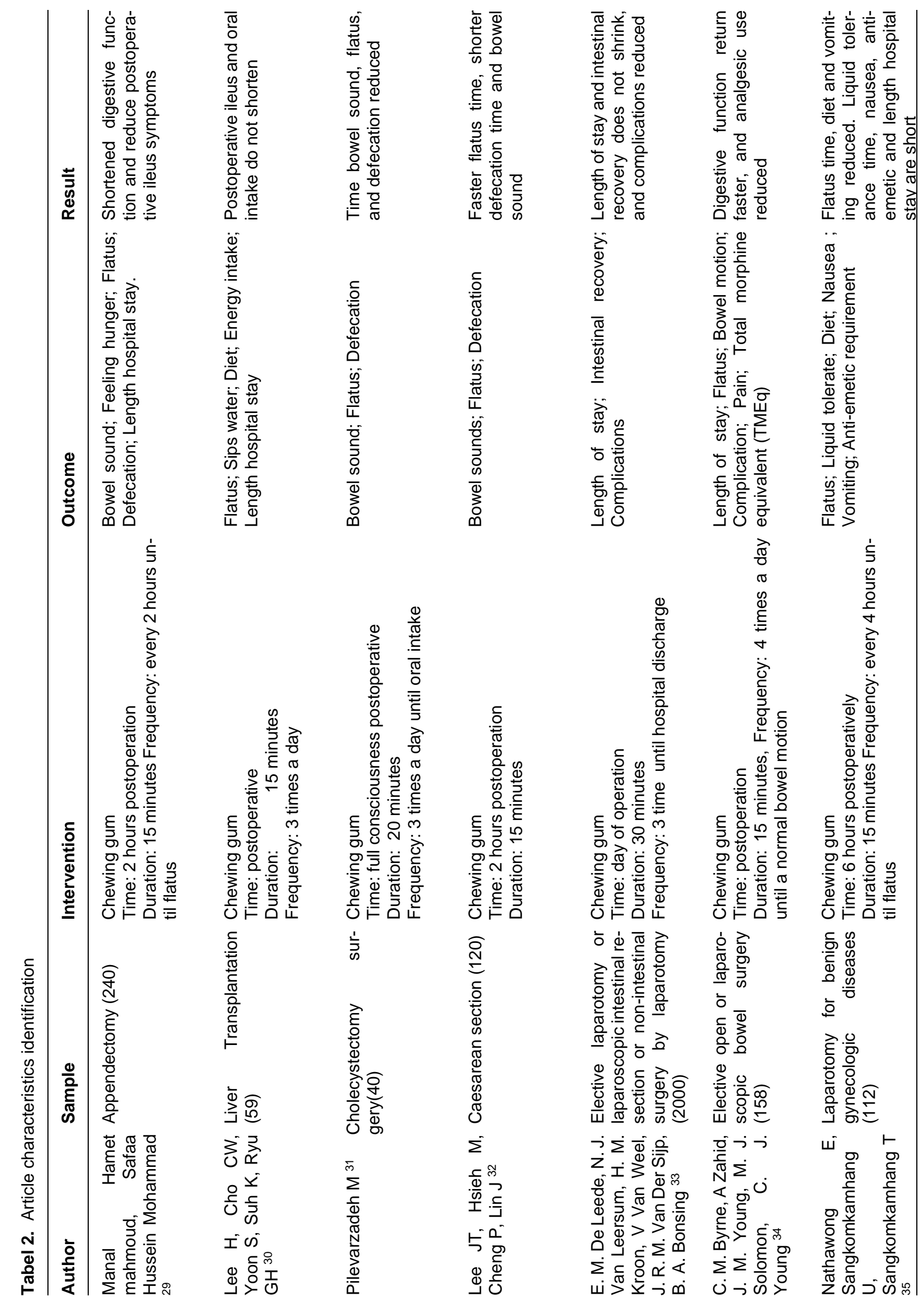




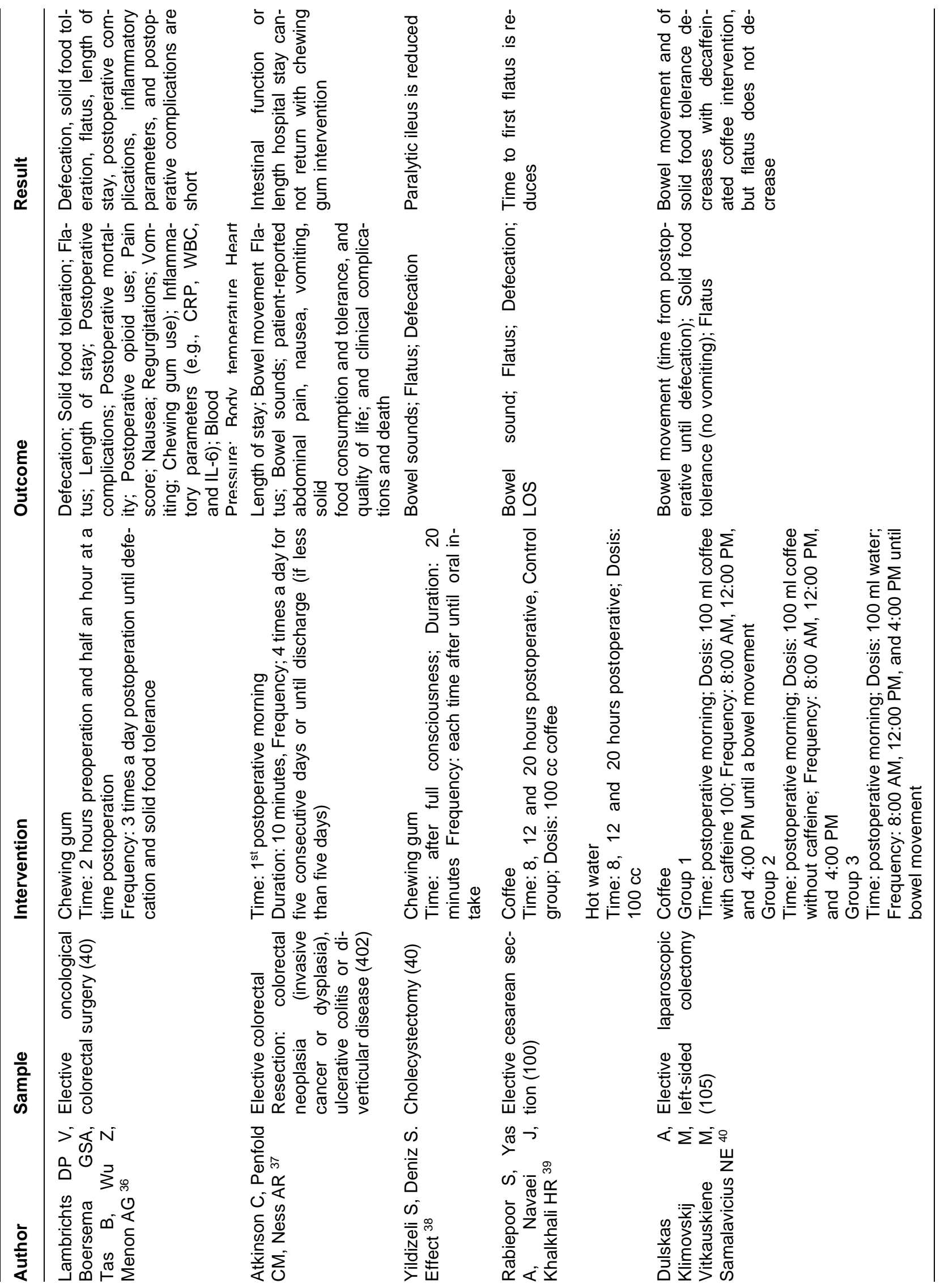




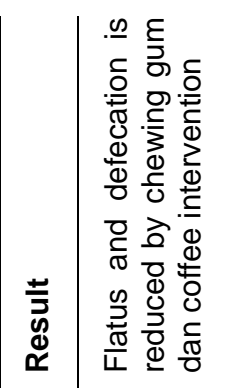

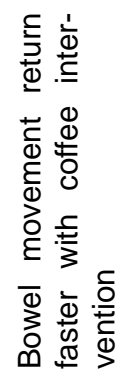
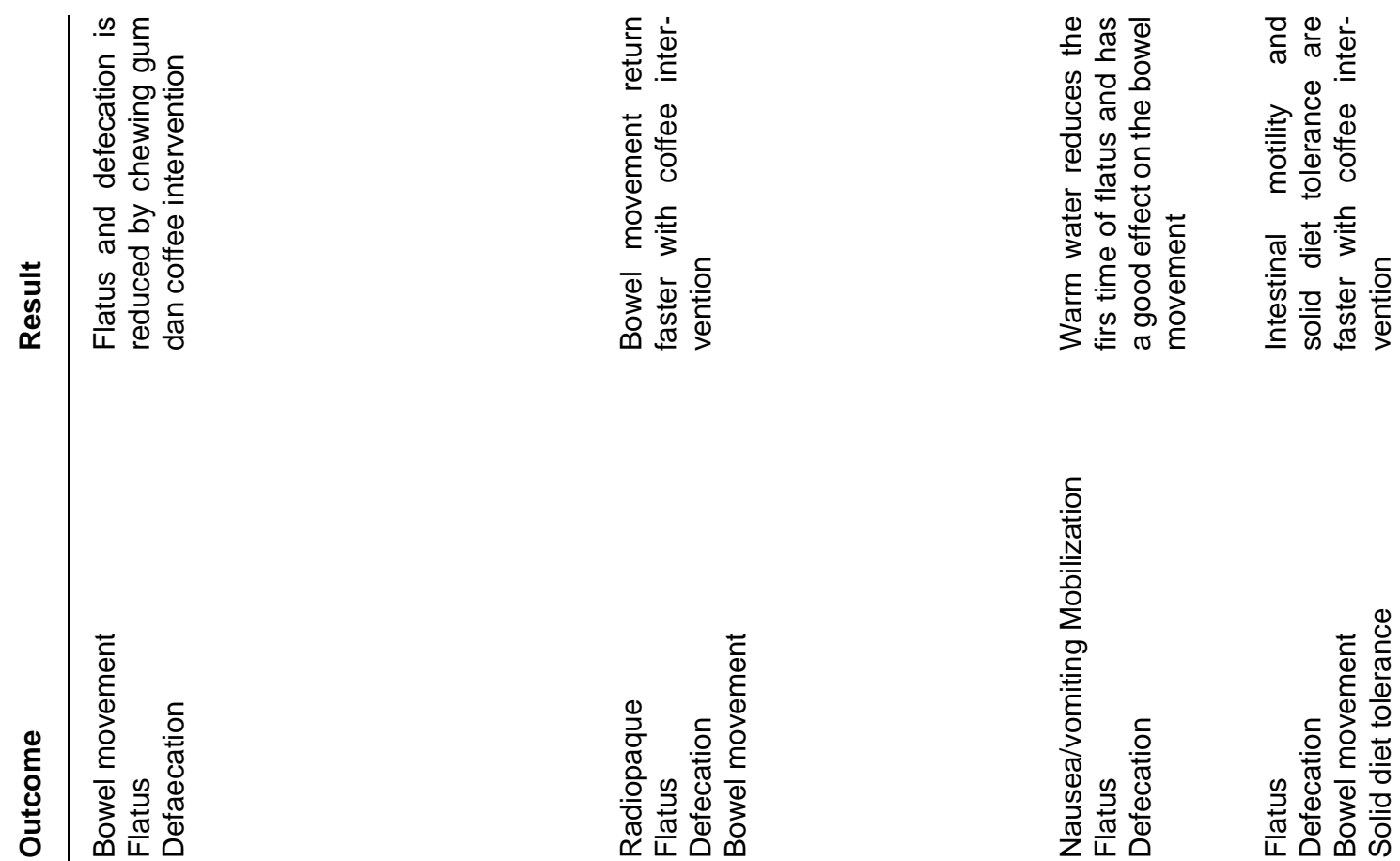

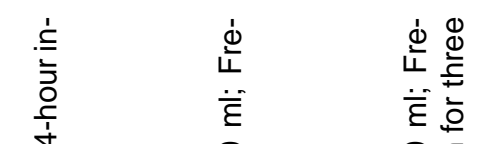

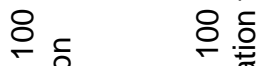

ip

해유

要

i。

要

离颉

需要

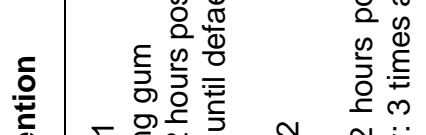

空弯

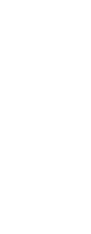

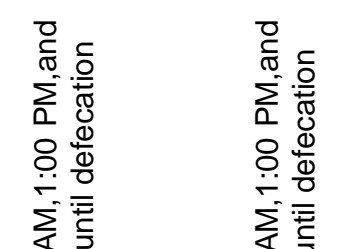

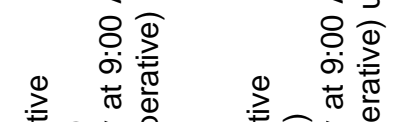

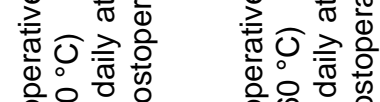

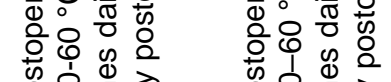

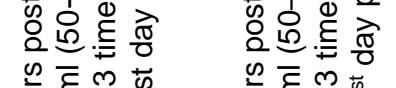

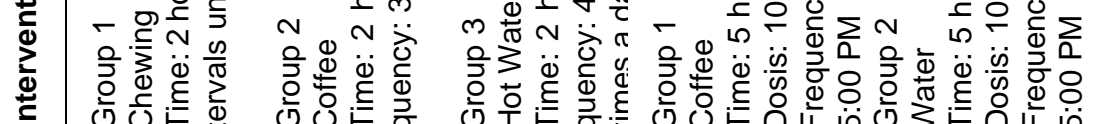

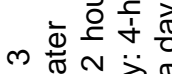

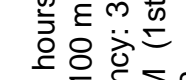

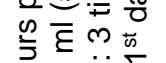

$2 \frac{1}{4}$

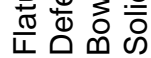

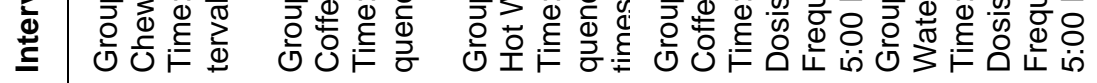

$\stackrel{1}{\bar{\Phi}}$

응웡

剀

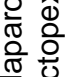

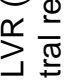

צ゙ぐく

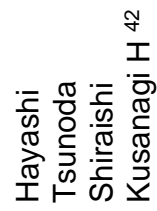

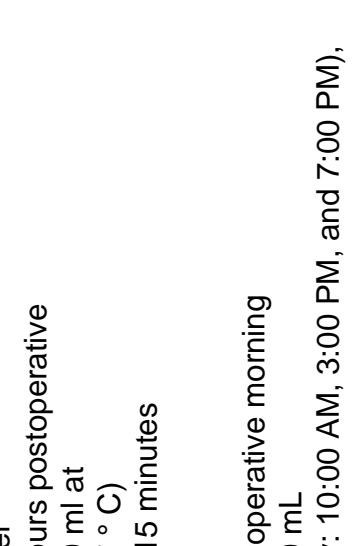

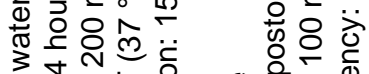

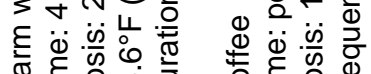

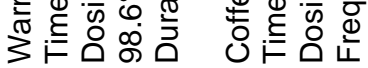

这兽

응 층

这

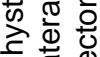

$\frac{\overline{0}}{\overline{0}}$

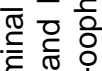

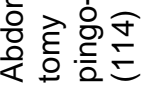

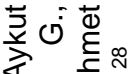

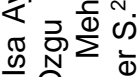

एं कि

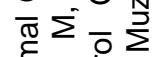

要, 


\section{Outcome}

\section{Chewing gum}

The result of 11 articles on chewing gum intervention showed the first time bowel noise, flatus, defecation, and LOS faster than standard hospital interventions. First study got the first time bowel sounds in the intervention group (mean $=10.05, S D=1.44$ ) faster than the control group (mean $=15.22, S D=2.02$ ), first time flatus in the intervention group (mean $=19.46, \mathrm{SD}=1.87$ ) faster than the control group (mean $=24.43, S D=1.80)$, the first defecation time in the intervention group (mean $=19.74, \mathrm{SD}$ $=1.84$ ) faster than the control group (mean $=31.03, \mathrm{SD}=$ $8.28)$, LOS time in the intervention group (mean $=28.81$, $S D=12.13)$ faster than the control group (mean $=35.63$, $\mathrm{SD}=7.32)^{29}$.

The second study found the results of the first time flatus in the intervention group (69.0 (66.1- 82.9) hours) faster than the control group (72.0 (57.6-77.2) hours), the LOS time in the intervention group (21 (15-37) days) more quickly than the control group (26 (16-42) days) ${ }^{30}$. The third study found that the first flatus time in the intervention group ( $21.05 \pm 12.8$ hours) was faster than the control group ( $40.8 \pm 15.9$ hours), the first time defecation in the intervention group (38.1 \pm 29.8 hours) was faster than the control group (58.25 \pm 18.6 hours). The first time bowel noise in the intervention group ( $4 \pm 0.02$ hours) was faster than the control group $(1.9 \pm 1.2 \text { hours })^{31}$.

The fourth study found that the first time bowel noise in the intervention group of chewing xylitol gum ( $6.9 \pm 1.7$ hours) faster than the intervention group of chewing regular gum (8.0 \pm 1.6 hours) more quickly than the control group (12.8 \pm 2.5 hours). The first time flatus in the intervention group of chewing xylitol gum (16.6 \pm 2.9 hours) faster than the intervention group of chewing regular gum (17.5 \pm 2.6 hours) more quickly than the control group $(24.3 \pm 4.5$ hours), the first time defecation in the intervention group of chewing Xylitol gum $(42.2+5.6$ hours) was faster than the intervention group of chewing regular gum (42.4 \pm 6.2 hours) faster than the control group ( $43.4 \pm 6.9$ hours) ${ }^{32}$.

The fifth study found the first time flatus in the intervention group (23 (14-45) hours faster than the control group (24 (13-48) hours), the first time defecation in the intervention group (52 (29-79) hours) faster than the control group (60 (25-88) hours). The LOS in the intervention group (7 (510) days) was the same as the control group (7 (5-10) hours) ${ }^{33}$. The sixth study got the results of the first time flatus in the intervention group (42.0 (2.9) hours) was faster than the control group (58.0 (8.2) hours), LOS in the intervention group (5.8 days) was faster than the control group (6.1 days) ${ }^{34}$.

The seventh study got the results of the first time flatus in the intervention group $(20.3 \pm 8.4$ hours $)$ faster than the control group ( $27.3 \pm 7.9$ hours), LOS in the intervention group (6.1 \pm 0.3 hours) more quickly than the control group $\left(6.1 \pm 0.4\right.$ hours) ${ }^{35}$. The eighth study found the first time flatus in the intervention group of chewing nicotine gum (1.00 [1.00-1.00] hours) faster than the intervention group of chewing regular gum (1.00 [1.00-22.25] hours), the first time defecation of intervention group of chewing nicotine gum (3.00 [1.75-4.00] hours) faster than the intervention group of chewing regular gum (3.00 [1.75-5.00] hours), LOS in the intervention group of chewing nicotine gum (4.50 [4.00-6.00] days) faster than the intervention group of chewing regular gum (5.50 [4.00-8.50] days) ${ }^{36}$.

The ninth study found that the first time bowel noise in the intervention group (2 (1-3) hours) was the same as the standard intervention group (2 (1-3) hours), the first time flatus in the intervention group (2 (2-3) hour) is the same as the standard intervention group (2 (1-3) hours). LOS in the intervention group (2 (1-3) hours) was faster than the standard intervention group (3 (1-4) hours) ${ }^{37}$. The tenth Study got the results of the first time flatus in the intervention group chewing gum ( $42.33 \pm 1.42$ hours) faster than the control group ( $49.20 \pm 1.42$ hours), the results of the first time defecation in the intervention group chewing gum (66.07 \pm 2.36 hours) faster than the control group (78.37 \pm 1.62 hours) ${ }^{37}$.

The eleventh study got the result of the first time flatus in the intervention group (51.07 \pm 19.63 hours) faster than the control group $(87.83 \pm 25.89$ hours). The first time defecation in the intervention group $(73.33 \pm 30.29$ hours $)$ were faster than the control group (137.20 \pm 44.05 hours), and LOS in the intervention group (7.63 \pm 1.47 faster than the control group $(9.47 \pm 2.67 \text { hours })^{38}$.

\section{Coffee and warm water}

There were six articles on coffee and mild water intervention. First, the first study found that the first time bowel noise in the coffee intervention group (5.84 \pm 1.41 hours) was faster than the warm water intervention group (6.16 \pm 1.33 hours). The first time flatus in the coffee intervention group (17.28 \pm 4.44 hours) faster than the warm water intervention group (22.54 \pm 5.09 hours), the first time defecation in the coffee intervention group (37.22 \pm 16.31 hours) was faster than the warm water intervention group $(36.82 \pm 16.35 \text { hours })^{39}$.

The second study found that the first time bowel noise in the decaffeinated coffee intervention group (3.00 \pm 1.50$)$ was faster than the caffeine coffee intervention group (3.75 \pm 1.53 ) shorter than the drinking water group (4.14 \pm 1.15$)$. The time first flatus in the decaffeinated coffee group ( 1.47 hours) was faster than the caffeine coffee group (1.57 hours) faster than the drinking water group (1.77 hours). The LOS in the caffeinated coffee intervention group (6.0 days) was faster than the decaffeinated coffee intervention group (6.6) faster than the drinking water group (7.0 days) 40. 
Third research got the first time result of intestinal noise in the chewing gum intervention group (300 (150-500)) faster than the coffee intervention group (320 (205-590)) more quickly than the warm water intervention group (385 (280580)) more rapidly than the control group (405 (188-680) $\mathrm{s})$, the first time flatus in the intervention group chewing gum (360 (200-600)) more quickly than the coffee intervention group (420 (300-650)) faster than the warm water intervention group (490 (345-705)) more rapidly than the control group (600 (380-903)), the first time defecation in the intervention group of chewing gum (802 (710-930)) longer than the intervention group of coffee (776 (502$960)$ ), longer than the warm water intervention group (737 $(490-910))$ and faster than the control group (980 (8041010)) ${ }^{41}$.

The fourth study found that the first time bowel noise in the intervention group $(35.6 \pm 5.4)$ was faster than the control group $(47.5 \pm 11.7)$, the first time flatus in the intervention group $(29.7 \pm 4.9)$ was faster than the control group (41.6 \pm 10.9 ). The first time defecation in the intervention group $(42.0 \pm 6.8)$ was faster than the control group $(59.8 \pm 14.6)$, and LOS in the intervention group $(6.1 \pm 1.1)$ was faster than the control group $(7.4 \pm 2.9)^{28}$. The fifth study got the results of the first time flatus in the coffee intervention group $(55.1(19.1,114.0))$ was faster than the water intervention group $(69.7(20.7,141.6))$, the first time defecation in the coffee intervention group $(9.3(0.5,47.1))$ was faster than the water intervention group $(12.6(1.1,46.1)){ }^{42}$.

An article about the intervention of consuming warm water in the study got the result of the first time flatus in the intervention group (11.0 \pm 4.2 hours) faster than the control group (18.6 \pm 6.0 hours), the first time defecation in the intervention group ( $35.4 \pm 12.5$ hours) was faster than the control group (38.1 \pm 12.7 hours) and LOS in the intervention group ( $24.4 \pm 7.6$ hours) was faster than the control group (23.8 \pm 4.8 hours) ${ }^{22}$.

\section{DISCUSSION}

This systematic review was compiled based on the identification of 19 articles with RCTs method about the effect of chewing gum intervention, consuming coffee, and warm water to decrease the incidence of postoperative ileus in postoperative abdominal patients. Postoperative ileus is a postoperative abdominal complication characterized by prolonged bowel sounds, flatus, defecation, and causes LOS. Postoperative ileus is a cessation of intestinal motility in a coordinated and temporary manner after surgery to prevent the removal of the bowel of tolerance of oral diet contents ${ }^{43}$. Some degree of postoperative ileus is not pathological response but a physiological and reasonable response to abdominal surgery according to some opinions in general ${ }^{5}$. Typical values for determining between pathological postoperative ileus there is still no significant opinion.
The duration of pathological postoperative ileus varies from 1-7 days, according to the researchers ${ }^{17}$. The results of physiological studies explained that gastric motility returned at 24-48 hours, small intestinal motility at 12-24 hours, and colonic motility at 3-5 days ${ }^{45}$. Postoperative ileus requires appropriate action in overcoming problems arising from its pathological effects. The cooperation of all health workers is needed to achieve optimal digestion recovery and reduce the length of stay. Appropriate planning and communication are also required to develop as evidence-based standard operational procedure than is followed and carried out; there have been several interventions designed to reduce the number and timing of postoperative ileus lately ${ }^{44}$.

Nineteen articles have identified in this systematic review that proved that the intervention of chewing gum, coffee, and consuming warm water could speed up the first time bowel sounds, flatus, defecation, and shortening LOS in postoperative abdominal patients. Chewing gum, coffee, and consuming warm water interventions are safe, inexpensive, secure. Without side effects, so they can be recommended as additional interventions on standard operational procedures in postoperative abdominal patients. The clinical characteristics of ileus are abdominal distension, inability to expel flatus, defecation, and defecation pain. These conditions can inhibit recovery, increase the LOS, and higher cost of care ${ }^{37}$. Sham feeding with gum is a safe, inexpensive, and convenient method to reduce postoperative abdominal ileus surgery ${ }^{15}$.

Chewing gum and coffee consumption are comfortable, safe, and tolerable methods and reported to increase postoperative gastrointestinal motility ${ }^{46}$. Chewing gum can increase intestinal motility by directly activating vagal cephalic reflexes that activate bowel myoelectric motion and stimulates the secretion of gastrointestinal hormones indirectly so that saliva and pancreatic fluid are produced; these reactions can encourage hormones and nerves to activate intestinal motility ${ }^{29}$.

The intervention of consuming warm water in postoperative patients also has a positive effect on intestinal motility such as, eliminating gastrointestinal spasm and restoring intestinal peristalsis ${ }^{22}$. When heat-sensitive receptors in the hypothalamus stimulated, the effector's system emits a signal which causes peripheral vasodilation and perspiration. Medulla oblongata, as the vasomotor center of the brain stem, regulates changes in the shape of blood vessels, vasodilation of blood vessels is influenced by anterior hypothalamic. As a result of vasodilatation of blood vessels will increase the blood flow of splanchnic (blood vessels of the gastrointestinal system).

The increased blood flow will carry the hormones that have been released by endocrine gland cells such as gastrin and motilin in the blood to circulated. These hormones will 
have an excitatory effect along the intestinal wall and smooth muscle, causing intestinal motility ${ }^{47}$. At the same time, coffee is a beverage that is known globally and has positive effects on health, including the cardiovascular system and central nervous system, as well as increasing feelings of comfort. According to Cohn, coffee has a good influence on the peristaltic and intestinal motility index when taken by adults ${ }^{39,48-50}$.

Intervention procedure of chewing gum (sugar-free gum) was given 2 hours before surgery and or 2-6 hours after surgery for 15-30 minutes, giving frequency every 2-4 hours once a day until flatus and defecation appear or up to 5 days (if the patient comes home before five days). The intervention procedure for consuming warm water was given 4 hours after surgery for 15 minutes as much as 200 $\mathrm{ml}$ with a temperature of $37^{\circ} \mathrm{C}$, the frequency of providing water was every 4 hours until bowel sounds, flatus or defecation appears. The coffee intervention procedure was given six hours- 1 days after surgery, as much as $100 \mathrm{ml}$ of decaffeinated coffee, the frequency of giving coffee was every 2-4 hours until bowel sounds, flatus or defecation appear.

The weaknesses in this systematic review were first; respondents who included in all cases of abdominal and non-intestinal abdominal surgery have not homogenized in any of the cases. Second, there was only one article about consuming warm water after surgery, so it cannot strengthen evidence of warm water in reducing postoperative abdominal ileus. Third, not all items included outcomes of first-time bowel noise, flatus, defecation, and overall length of stay.

\section{CONCLUSIONS AND RECOMMENDATION}

Postoperative abdominal ileus characterized by abdominal distension, prolonged bowel sounds, flatus, and defecation can be reduced by chewing gum intervention, consuming warm water, and coffee. The invasion of chewing gum, drinking coffee, and warm water enhances the recovery of digestive function by accelerating the first time bowel sounds, flatus, defecation, and the Length of Stay of postoperative abdominal patients. The intervention is safe, comfortable, secure, and no side effects, so it can be recommended as a standard operational intervention procedure in postoperative gastric patients.

\section{REFERENCES}

1. Brenner ZR. Preventing postoperative complications. J Nurs Manag. 2000;31(12):17-22.

2. Sayek I. Basic Surgery. Ankara, Turkey: Günes, Bookstore; 2004.

3. Yang P, Long WJ, Li W. Chewing Xylitol Gum could Accelerate Bowel motility Recovery after Elective Open Proctectomy for Rectal Cancer.
2018;70(1):53-58. doi:10.24875/RIC.18002428

4. Kehlet $H$. Postoperative ileus, an update on preventive techniques. Nat Clin Pract Gastroenterol Hepatol. 2008;5(10):552-558. doi:10.1038/ncpgasthep1230

5. Miedema BW, Johnson JO. Methods for decreasing postoperative gut dysmotility. Lancet Oncol. 2003;4(6):365-372. doi:10.1016/S14702045(03)01118-5

6. Nanthawong, Sangkomkamhang, \& Sangkomkamhang T. Gum Chewing for Stimulating Early Recovery of Bowel Function after Postoperative Benign Gynecologic Surgery, A Randomized Controlled Trial. 2016;24(4):247-254.

7. Chapuis P, Bokey L, Keshava A, Rikard M, Young $C$, Dent O. Risk factors for prolonged ileus after resection of colorectal cancer: an observational study of 2400 consecutive patients. Ann Surg. 2013;257(5):909-915.

doi:10.1097/SLA.0b013e318268a693

8. Moghadamyeghaneh Z, Hwang GS, Hanna M., Stamos MJ. Risk factors for prolonged ileus following colon surgery. Surg Endosc. 2016;30(2):603-609. doi:10.1007/s00464-0154247-1

9. Svatek RS, Fisher MB, Williams MB, NoguerasGonzales GM, Urbauer DL, Dinney CP. Age and body mass index are independent risk factors for the development of postoperative paralytic ileus after radical cystectomy. Urology. 2010;76(6):1419-1424.

doi:10.1016/j.urology.2010.02.053

10. Vather R, Josephson R, Jaung R, Robertson J, Bissett I. Development of a risk stratification system for the occurrence of prolonged postoperative ileus after colorectal surgery: a prospective risk factor analysis. Surgery. 2015;157(4):764-773. doi:10.1016/j.surg.2014.12.005

11. Artinyan A, Nunoo-Mensah JW, Balasubramaniam $\mathrm{S}$, Beart Jr RW. Prolonged postoperative ileusdefinition, risk factors, and predictors after surgery. World J Surg. 2008;32(7):1495-1500. doi:10.1007/s00268-008-9491-2

12. Millan M, Biondo S, Fraccalvieri D, Kreisler A. Risk factors for prolonged postoperative ileus after colorectal cancer surgery. World $J$ Surg. 2012;36(1):179-185. doi:10.1007/s00268-0111339-5

13. Vather R, Trivedi S, Bissett I. Defining postoperative ileus: results of a systematic review and global survey. J Gastrointest Surg. 2013;17(5):962-972. doi:10.1007/s11605-0132148-y

14. Kim JM, Min GE, Yoo KH, Chang S-G, Jeon SH. Risk factors for postoperative ileus after urologic laparoscopic surgery. J Korean Surg Soc. $2011 ; 80(6): 384-389$. doi:10.4174/jkss.2011.80.6.384

15. Lee, Chan, Susie, Suh, Yoon, \& Geol H. Effect of sham feeding with gum chewing on postoperative ileus after liver transplantation - a randomized controlled trial. 2016;30(9):1501-1507. doi:10.1111/ctr.12849

16. Tazegul, Secilmisa, Dogan, Yilmaz, Kebabcilar, Gencoglu, \& Celik C. Gum chewing reduces the 
time to first defaecation after pelvic surgery: A randomised controlled study Analyzed per protocol Analyzed per protocol. J Obstet Gynaecol. 2014:35(5):494-498. doi:10.3109/01443615.2014.970146

17. Venara, Neunlist, Slim, Barbieux, Colas, Hamy S. Postoperative ileus: Pathophysiology, incidence, and prevention. J ViscSurg. 2016;153 (6):439-446 .

18. Muphy, Tevis, Kennedy S. Independent Risk Factors For Prolongged Operative lleus Development. JSurg Res. 2016;201(2):279-285. doi:10.1016/j.jss.2015.10.047

19. Holte K, Kehlet H. Postoperative Ileus, progress towards effective management. Drugs. 2002;62(12):2603-2615. doi:10.2165/00003495200262180-00004

20. Leier $\mathrm{H}$. Does gum chewing help prevent impaired gastric motility in the postoperative period? $\mathrm{J} \mathrm{Am}$ Acad Pract. 2007;19(3):133-136. doi:10.1111/j.1745-7599.2006.00209.x.

21. Luckey A, Livingston E, Tache Y. Mechanisms and treatment of postoperative ileus. Arch Surg. 2003;138(2):206-214.

doi:10.1001/archurg.138.2.206

22. Caliskan N, Bulut H, Konan A. The Effect of Warm Water Intake on Bowel Movements in the Early Postoperative Stage of Patients Having Undergone Laparoscopic Cholecystectomy, A Randomized Controlled Trial. 2016;39(5):340-347. doi:10.1097/SGA.0000000000000181

23. Yılmaz M. Effect of planned pre-operative teaching on the occurrence of post-operative complications and patient satisfaction. Turkish J Res Dev Nurs. 2002;4(1):40-50.

24. Fearon $\mathrm{KCH}$, Ljungqvist $\mathrm{O}$, Von Meyenfeldt $\mathrm{M}$, et al. Enhanced recovery after surgery: A consensus review of clinical care for patients undergoing colonic resection . Clin Nutr. 2005;24(2):466-477. doi:10.1016/j.clnu.2005.02.002

25. Junger M, Schoenberg MH. Postoperative care in fasttrack rehabilitation for elective colonic surgery. Transfus Altern Transfus Med. 2007;9(1):66-77. doi:10.1111/j.1778-428X.2007.00047.x.

26. Quin W, Neill J. Evidence for early oral feeding of patients after elective open colorectal surgery: A literature review. J Clin Nurs. 2006;15(6):696-709. doi:10.1111/j.1365-2702.2006.01389.x

27. Zhou T, Wu XT, Zhou YJ, Huang X, Fan W, Li YC. Early removing gastrointestinal decompression and early oral feeding improve patients' rehabilitation after colorectostomy. World $J$ Gastroenterol. doi:10.3748/wjg.v12.i15.2459

28. Kemal Gungorduk M, Isa Aykut Ozdemir M, Ozgu Gungorduk M, Varol Gulseren M, Mehmet Gokçu M, Muzaffer Sancı M. Effects of coffee consumption on gut recovery after surgery of gynecological cancer patients: a randomized controlled trial. 2017;216(2):145.e1-e7. doi:10.1016/j.ajog.2016.10.019

29. Mahmoud MH, Mohammad SH. Chewing gum for declining ileus and accelerating gastrointestinal recovery after appendectomy. 2018;5(4):277-284. doi:10.1515/fon-2018-0038

30. Lee H, Cho CW, Yoon S, Suh K, Ryu GH. Effect of sham feeding with gum chewing on postoperative ileus after liver transplantation a randomized controlled trial. Clin Transplant. 2016;30(9):15011507. doi:10.1111/ctr.12849

31. Pilevarzadeh M. Effect of Gum Chewing in the Reduction of Paralytic lleus Following Cholecystectomy. 2016;9(1):405-409.

32. Lee JT, Hsieh M, Cheng P, Lin J. The Role of Xylitol Gum Chewing in Restoring Postoperative Bowel Activity After Cesarean Section. 2016;18(2):167172. doi: $10.1177 / 1099800415592966$

33. Leede EM De, Leersum NJ Van, Kroon HM, Weel V Van, Sijp JRM Van Der, Bonsing BA. Multicentre randomized clinical trial of the effect of chewing gum after abdominal surgery. BJS. 2018;105(7):19. doi:10.1002/bjs.10828

34. Byrne CM, Zahid A, Young JM, Solomon MJ, Young CJ. Gum Chewing Aids Bowel Function Return and Analgesic Re quirements After Bowel Surgery: A Randomised Controlled Trial. 2017. doi:10.1111/ijlh.12426

35. Nathawong E, Sangkomkamhang $U$, Sangkomkamhang T. Gum Chewing for Stimulating Early Recovery of Bowel Function after Postoperative Benign Gynecologic Surgery: A Randomized Controlled Trial. Thai $J$ Obstet Gynaecol. 2016;24(4):247-254.

36. Lambrichts DP V, Boersema GSA, Tas B, Wu Z, Menon AG. Nicotine chewing gum for the prevention of postoperative ileus after colorectal surgery : a multicenter, double-blind, randomised controlled pilot study. int $J$ Color Dis. 2017;32(9):1267-1275. doi:10.1007/s00384-0172839-z

37. Atkinson C, Penfold CM, Ness AR, et al. Randomized clinical trial of postoperative chewing gum versus standard care after colorectal resection. $\quad 2016 ; 33 \quad$ (1):962-970. doi:10.1002/bjs.10194

38. Yildizeli S, Deniz S. Effect of gum chewing on reducing postoperative ileus and recovery after colorectal surgery: A randomised controlled trial. Complement Ther Clin Pract. 2016;23(2):21-25. doi:10.1016/j.ctcp.2016.02.001

39. Rabiepoor S, Yas A, Navaei J, Khalkhali HR. Does coffee affect the bowel function after caesarean section? Eur J Obstet Gynecol. 2017;220(7):96-99. doi:10.1016/j.ejogrb.2017.07.028

40. Dulskas A, Klimovskij $M$, Vitkauskiene $M$, Samalavicius NE. Effect of Coffee on the Length of Postoperative lleus After Elective Laparoscopic Left-Sided Colectomy: A Randomized, Prospective Single-Center Study. 2015;58(11):1064-1069. doi:10.1097/DCR.0000000000000449

41. Goymen A, Simsek Y, Oskaplan SE, et al. Effect of Gum Chewing and Coffee Consumption on Intestinal Motility in Caesarean Sections. 2017;(3):1-5. doi:10.4328/JCAM.4901

42. Hayashi K, Tsunoda A, Shiraishi A, Kusanagi $H$. Quantification of the effects of coffee on postoperative ileus after laparoscopic ventral rectopexy : a randomized controlled trial. Eur Surg. 2019;51(6):325-331. doi:10.1007/s10353-0190605-x

43. Augestad K, Delaney C. Postoperative ileus: 
impact of pharmacological treatment, laparoscopic surgery and enhanced recovery pathways. World J Gastroenterol. doi:10.3748/wjg.v16.i17.2067

44. Livingston EH, Passaro Jr EP. Postoperative ileus. Dig Dis Sci. 1990;35(1):121-232. doi:10.1007/bf01537233

45. Barletta JF, Senagore AJ. Reducing the Burden of Postoperative ileus : Evaluating and Implementing an Evidence-based Strategy. World J Surg. 2014;38(8):1966-1977. doi:10.1007/s00268-0142506-2

46. Short V, Herbert G, Perry R, et al. Chewing gum for postoperative recovery of gastrointestinal function. Cochrane Database Syst Rev. 2015;20(2):CD006506.

doi:10.1002/1464651858.CD006506.pub3

47. Sherwood. Fisiologi Manusia Dari Sel Ke Sistem. (6, ed.). Jakarta: EGC; 2011.
48. Eamudomkarn N, Kietpeerakool C, Kaewrudee S. Effect of postoperative coffee consumption on gastrointestinal function after abdominal surgery : A systematic review and meta- analysis of randomized controlled trials. Sci Rep. 2018;8(11):1-10. doi:10.1038/s41598-018-357522

49. Cornwall HL, Edwards BA, Curran JF, Boyce S. Coffee to go? The effect of coffee on resolution of ileus following abdominal surgery: A systematic review and meta-analysis of randomised controlled trials. Clin Nutr. 2019;300(6):1-10. doi:10.1016/j.clnu.2019.06.003

50. Kane TD, Tubog TD, Schmidt JR. The Use of Coffee to Decrease the Incidence of Postoperative Ileus: A Systematic Review and Meta-Analysis. $J$ PeriAnesthesia Nurs. 2019;300(7):1-8. doi:10.1016/j.jopan.2019.07.004 